\title{
Bradykinin promotes migration and invasion of human immortalized trophoblasts
}

\author{
Rafaela Erices ${ }^{1}$, Jenny Corthorn ${ }^{1,2}$, Francisco Lisboa ${ }^{1}$ and Gloria Valdés ${ }^{1,2^{*}}$
}

\begin{abstract}
Having demonstrated that the bradykinin B2 receptor (B2R) is expressed in cells that participate in trophoblast invasion in humans and guinea-pigs, we investigated the role of bradykinin (BK) on cell migration and invasion in the HTR-8/SVneo trophoblast cell line using wound healing and invasion assays. First, we documented that HTR-8/ SVneo cells expressed kallikrein, B2R, B1R, MMP-2 and MMP-9 using immunocytochemistry. Incubation with BK (10.0 microMol/L) for 18 hours increased the migration index 3-fold in comparison to controls or to cells preincubated with the B2R antagonist HOE-140. BK (10.0 microMol/L) incubation yielded a similar number of proliferating and viable cells as controls, therefore the enhanced closure of the wound cannot be attributed to proliferating cells. Incubation with BK (10.0 microMol/L) for 18 hours increased the invasion index 2-fold in comparison to controls or to cells preincubated with the antagonist of the B2R. Neither the B1R ligand Lys-des-Arg9 BK, nor its antagonist Lys-(des-Arg9-Leu8), modified migration and invasion. Further support for the stimulatory effect of B2R activation on migration and invasion is provided by the 3 -fold increase in the number of filopodia per cell versus controls or cells preincubated with the B2R antagonist. Bradykinin had no effect on the cellular protein content of the B2R, nor the MMP-9 and MMP-2 gelatinase activity in the culture media varied after incubation with BK. This study adds bradykinin-acting on the B2R-to the stimuli of trophoblast migration and invasion, an effect that should be integrated to other modifications of the kallikrein-kinin system in normal and pathological pregnancies.
\end{abstract}

\section{Background}

In humans, the invasion of maternal decidua and uterine spiral arteries by the extravillous trophoblast (EVT) is essential for the establishment of a normal placenta and adequate blood flow to the fetus. On the maternal side, EVT invasion is initiated when cytotrophoblasts anchor the budding placental villi to the uterine wall; in a second stage, EVTs detach and migrate across the endometrium, transform the arteries, and finally settle in their lumen [1-3]. Simultaneously, on the fetal side, villous cytotrophoblasts establish a richly branching tree that provides the extensive surface in which fetal and maternal blood exchange nutrients and waste products.

Dysregulation of trophoblast invasion is associated with various pathologies, such as intrauterine growth retardation, preterm birth, placenta accreta and the preeclampsia syndrome, its foremost clinical manifestation [4-7]; all these complications increase maternal and fetal

\footnotetext{
*Correspondence: gvaldes@med.puc.cl

${ }^{1}$ Centro de Investigaciones Médicas, Escuela de Medicina Pontificia

Universidad Católica, Santiago, Chile

Full list of author information is available at the end of the article
}

morbidity and mortality. Over the years proteolytic, adhesive, growth promoting, inflammatory and angiogenic molecules that modulate trophoblast migration and invasion have been identified, and localized in trophoblasts, maternal epithelial and stromal cells, uterine NK cells and macrophages [8-13]. The list of factors controlling trophoblast invasion in normal placentation is continuously expanding, but despite intensive research, our understanding of normal and pathological processes remains limited.

It has been postulated that nitric oxide $(\mathrm{NO})$ regulates trophoblast invasion by priming the maternal blood vessels $[1,14]$. We have hypothesized that NO integrates a network of vasodilator systems including the kallikreinkinin system (KKS), which includes serine proteases, and tissue and plasma kallikrein (Kal), that generate kallidin and bradykinin from low and high molecular kininogen, respectively [15]. The upregulation of Kal and endothelial nitric oxide synthase (eNOS) in placenta accreta, a condition of exaggerated trophoblast invasion, suggested that vasodilators facilitate trophoblast migration [16]. However, the tissue KKS, initially considered a

\section{Ciomed Central}


vasoactive system, is now known to have pleiotropic effects which deserve to be studied in pregnancy.

Bradykinin (BK)-related peptides activate G-protein coupled receptors, the bradykinin type 1 and type 2 receptors (B1R and B2R) [17,18]. B1Rs are inducible, and their natural agonist lacks the $\mathrm{C}$-terminal Arg residue of BK; they cause chronic inflammation, pain, hypotension and proliferation of tumoral cells. They are exceptionally constitutive in the central nervous system, and information on their actions is derived from pharmacological studies. B2Rs are constitutive, require the full peptide chain and activate endothelial cells leading to vasodilatation, increased vascular permeability, production of NO, and mobilization of arachidonic acid. They are localized in endothelial cells, smooth muscle, fibroblasts, mesangial cells, neurons, astrocytes, and polynuclear neutrophils. In reproductive tissues the B2R has been documented in decidua, placental and extravillous trophoblasts, and in the fetal endothelium in humans, rats and guinea-pigs [19-23].

Bradykinin stimulates cell migration, a critical process in placentation, embryogenesis, wound healing, immune response, tissue development, vascular disease and cancer [24-27]. BK increases migration of endothelial cells [28], endothelial progenitor cells [29], neutrophils [30,31], lymphocytes [32], fibroblasts [33], dendritic cells [34], microglia [35], and cancer cells [36-38]. Interestingly, BK has been found to induce the formation of peripheral actin microspikes, filopodia and lamellipodia in fibroblasts and endothelial progenitor cells, indicating its relevance in determining an invasive phenotype [33]. Whether the effects are mediated by the B1R or the B2R depends on the different cell types.

In addition, activation of the BK receptors stimulates metalloproteinases, key molecules in trophoblast invasion. In rat, astroglial cell line activation of the B2R modulates MMP-9 gene expression and cell migration by phosphorylating and translocating the protein kinasedelta-dependent extracellular kinase1/2, which in turn activates its downstream factor Elk-1 [39]. On the other hand, B1R stimulation induces release of MMP-2 and MMP-9 via an ERK-dependent pathway in estrogen-sensitive and-insensitive breast cancer cells [37].

The aim of the present study was to evaluate the effect of bradykinin on the migratory and invasive capacity of HTR-8/SVneo cells, an immortalized line of first trimester extravillous trophoblast, which constitutes a valid model for extravillous trophoblasts [40-43]. First, we confirmed the main components of the KKS in these cells. We identified the B2R as the receptor involved in the BK-stimulated migratory and invasive capacity of these cells. Lastly, we demonstrated that BK induced filopodias, a characteristic conformation of the cytoskeleton in migrating cells.

\section{Methods}

\section{HTR-8/SVneo cell culture}

HTR-8/SVneo trophoblast cells were kindly donated by C.H. Graham, Queen's University, Kingston, Canada. The cells were obtained from first trimester human placenta (8-10 wk gestation) and immortalized by transfection with a cDNA construct that encodes the simian virus 40 large $\mathrm{T}$ antigen. Though nontumorigenic and nonmetastatic, the cells are highly invasive in vitro and exhibit phenotypic properties of extravillous cytotrophoblasts, including the expression of cytokeratins 7,8 , and 18, placental alkaline phosphatase, urokinase-type PAR, human leukocyte antigen (HLA) framework antigen W6/32, IGF-II mRNA and protein, and the integrin profile characteristic of invasive cytotrophoblasts [42]. When plated on Matrigel these cells express HLA-G [44].

Cells were cultured as described [40,41]. Briefly, cells were grown in RPMI 1640 (Sigma-Aldrich) supplemented with $10 \%$ FBS (Gibco) and $50 \mu \mathrm{g} / \mathrm{ml}$ gentamicin (Gibco) in a humidified atmosphere of $95 \%$ air and 5\% $\mathrm{CO} 2$ at $37^{\circ} \mathrm{C}$. Cells at passage $6-25$ were used to perform all the experiments.

\section{Immunocytochemistry}

Immunocytochemistry was performed for kininogen, Kal, B1R, B2R, MMP-2, MMP-9, cytokeratin and Ki67. The dilution and origin of the antibodies were: anti-kininogen (1:500, Boehringer); anti-Kal (1:2,000, produced in our laboratory [45]); anti-B1R (1:1,000, Santa Cruz Biotechnology), and anti-B2R mouse monoclonal $(1: 4,000$, BD Transduction Laboratories); anti-MMP-2 and antiMMP-9 (1:20 and 1:200 respectively, Calbiochem mouse mAb, USA); anti-pancytokeratin mouse monoclonal, (1:100, Sigma-Aldrich) and anti-Ki67 mouse monoclonal (1:50, BioGenex).

Cells were seeded at a density of 80,000 cells/well on cover slides in 24-well plates (Nucleon Surface, Nunc), in RPMI 1640, supplemented with $1 \%$ FBS, $50 \mu \mathrm{g} / \mathrm{ml}$ gentamicin in a humidified atmosphere of $95 \%$ air and $5 \% \mathrm{CO}_{2}$ at $37^{\circ} \mathrm{C}$. After 18 hours, cells were rinsed 3 times with cold PBS and fixed with methanol at $-20^{\circ} \mathrm{C}$ for 20 minutes, equilibrated 3 times with $50 \mathrm{mMol} / \mathrm{L}$ TRIS- $\mathrm{HCl}$ PBS buffer pH 7.8 and incubated with $10 \%$ $\mathrm{H}_{2} \mathrm{O}_{2}$ for 5 minutes to block endogenous peroxidases. Cells were incubated with protein block (Cas-Block, Zymed Laboratories) for 30 minutes in a humidified chamber, and incubated with the respective antibodies at the aforementioned concentrations for 18 hours at $4^{\circ}$ C. Cells were immunostained with the biotin-streptavidin peroxidase system (Dako LSAB+System-HRP), incubated with $0.1 \%$ of 3-3'-diaminobenzidine (SigmaAldrich) in the presence of $0.05 \% \mathrm{H}_{2} \mathrm{O}_{2}$ for 15 minutes, 
stained with Harris Haematoxylin (Sigma-Aldrich) and finally mounted with glycerin-gelatin (Kaisers, Merck).

To determine whether kininogen-the substrate from which kallikrein generates bradykinin-is an inherent or a trapped molecule, cells were incubated with or without serum for 24-hours. The specificity of the staining was determined by incubating sections in the absence of the first antibody, or in the presence of rabbit IgG fraction (1:50 to $1: 1000)$ and mouse IgG serum (1:50 to $1: 1,000$, both from Dako Cytomation), depending on the species in which the antibodies were generated.

\section{Western blot analysis}

Total proteins from HTR-8/SVneo cells were extracted using $20 \mathrm{mM}$ Tris- $\mathrm{HCl}$ buffer containing $10 \mathrm{mM}$ EDTA, $2 \mathrm{mM}$ phenylmethylsulfonylfluoride, $5 \mu \mathrm{M}$ leupeptin, 50 $\mu \mathrm{g} / \mathrm{ml}$ soybean trypsin inhibitor and $0.02 \% \mathrm{NaN} 3$ at $\mathrm{pH}$ 7.4. Lysed cells were left for 20 minutes on ice, centrifuged at $14,000 \mathrm{rpm}$ for 20 minutes at $4^{\circ} \mathrm{C}$ and finally stored at $-70^{\circ} \mathrm{C}$. Protein content was determined according to the Lowry method.

Western blot for the B2R was performed as previously described [46]. Equal amounts of protein (100 $\mu \mathrm{g} /$ lane) were separated using 10\% SDS-PAGE under reducing conditions and transferred to nitrocellulose membranes (Biorad, Hercules, CA), blocked with $5 \%$ nonfat dry milk in PBS-0.1\% Tween-20 buffer (PBS-T) and incubated overnight at $4{ }^{\circ} \mathrm{C}$ with the same primary antibody used in immunohistochemistry: anti-B2R mouse monoclonal (1:1000, BD Transduction Laboratories, USA) diluted in blocking buffer. The membranes were washed six times for five minutes in PBS-T buffer, incubated with HRPconjugated anti-mouse or anti-rabbit secondary antibodies (both 1:3000, Biorad, Hercules, CA) for one hour at room temperature and developed with chemiluminescence reagent (NEL-103, Western Lighting, PerkinElmer, MA) [30]. Membranes were exposed to CLxPosure film (Pierce, Rockford, IL). Equal protein loading was confirmed with Ponceau-S red staining (Sigma, St. Louis, MO). Images were scanned at 16-bit/600 dpi resolution with an Epson Perfection 3490 scanner (Epson Corporation, CA), saved as tiff files and calibrated to an optical density scale. The integrated optical density of bands was quantitated using the Image J v.1.34 software. The optical densities were expressed as the ratio of treatment/control.

\section{Proliferation and viability assays}

Cells were seeded at a density of 80,000 cells/well on cover slides in 24-well plates and incubated for 18 hours in medium $1 \%$ FBS with and without $10.0 \mu \mathrm{Mol} / \mathrm{L} \mathrm{BK}$ (Sigma-Aldrich). Immunocytochemistry was performed as previously described using antibody to Ki67, a nuclear protein expressed in the active phases of the cell cycle.
The proliferation index was represented by the percentage of cells with positive staining within total cells; the proliferation ratio represented the proliferation index of the treated/untreated cells in each experiment.

In addition, cell viability was evaluated using the MTS assay (Promega). Cells were placed in complete medium at a concentration of 15,000 cells/well in 96-well plates for 24 hours. To determine the effect of BK $10.0 \mu \mathrm{mol} / \mathrm{L}$ at different periods $(0,6,18,24$ hours $)$ cells were incubated in reduced serum with $1 \%$ FBS; the release of formazan was read after 2 hours of incubation with the MTS substrate at $495 \mathrm{~nm}$ by spectrophotometry (Multiskan EX, LabSystem).

All experiments were performed in triplicate and repeated at least three times.

\section{Migration assay}

Cell migration was studied using the wound-healing assay under the effect of bradykinin, the B1R agonist [Lys-des-Arg ${ }^{9}$ ] bradykinin (LDBK) and the B1R or/and B2R antagonists. HTR-8/SVneo cells $(100,000)$ were seeded in each well on cover slides in 24-well plates containing $500 \mu \mathrm{l}$ complete medium for 24 hours. Cells were then washed 3 times with PBS and the wound was generated by removing cells in the center of the well with a sterile pipette tip; the unattached cells were washed away with PBS. The experiments were performed in reduced serum (1\% FBS). Initially incubations in the different experimental conditions were carried out for 6, 18 and 24 hours. We then incubated for 18 hours, time in which maximal differences among treatments were observed. Cell migration was studied under the effect of $10.0 \mu \mathrm{Mol} / \mathrm{L}$ of bradykinin and of 10.0 $\mu \mathrm{Mol} / \mathrm{L}$ of the B1R agonist LDBK. In addition cells were preincubated for 30 minutes with B1R or/and B2R antagonists: $10.0 \mu \mathrm{Mol} / \mathrm{L}$ of Lys-(des-Arg ${ }^{9}-\mathrm{Leu}^{8}$ ) bradykinin (AB1R) and $10.0 \mu \mathrm{mol} / \mathrm{L}$ of D-Arg-Arg-ProHyp-Gly-Thi-Ser-D-Tic-Oic (HOE-140, Sigma-Aldrich), and then incubated with their respective ligand for 18 hours in all assays.

The migration assay was performed 4 times in duplicate. Three images were obtained along the wound with a Nikon TMS inverted microscope connected to a Nikon CoolPix 4500 camera and quantified using ImageJ v.1.34 software. The migration index was defined as cells migrating in response to each study condition divided by cells migrating in response to medium alone [43].

\section{Invasion assay}

Briefly, transwell inserts containing membranes with 8 $\mu \mathrm{m}$ pore size (Nunc) were coated with matrigel (BD Biosciences) as per the manufacturer's instructions. Cells $(30,000)$ were spread over the matrigel $(1: 10)$ in $200 \mu \mathrm{l}$ of medium with reduced serum (1\% FBS), and 
$800 \mu \mathrm{l}$ of culture medium was added to the lower chamber. Cell invasion was studied under the effect of BK, of BK plus two B2R antagonists-HOE-140 and the nonpeptide antagonist bradyzide (BDZ, Sigma)-and finally with the B1R agonist LDBK plus its antagonist AB1R; $\mathrm{BK}$, agonists and antagonists were all used at 10.0 $\mu \mathrm{Mol} / \mathrm{L}$. The cells were preincubated with the antagonists for 30 minutes and then with their respective ligands for 18 hours. Bradykinin, the B1R agonist, and the antagonists were added on the upper and lower chambers of the invasion well.

For assessing the number of invaded cells, the filters were stained with anti-cytokeratin antibody and haematoxylin and mounted on cover slides with Kaiser's, glycerin-gelatin (Merck). Each experiment was performed in duplicate and was repeated 4 times. The inserts were examined by a blinded observer with an AX.10 microscope (Carl Zeiss) attached to a Nikon CoolPix 4500 camera; 20 photographs, were obtained per insert, and the number of cells in the underside of the filter was counted. Results are expressed as invasion index, where the level of invasion was defined as cells invading in response to $\mathrm{BK}$ divided by cells invading in response to medium alone [43].

\section{Gelatin zymography}

Gelatinase activity was detected by zymography using methods described previously, with some modifications [46]. Cells were seeded at a density of 100,000 on plates in complete medium and incubated until $70 \%$ confluency was achieved; cells were further incubated in medium with reduced serum (1\% FBS) for $24 \mathrm{~h}$. BK was then added for $18 \mathrm{~h}$. Aliquots from conditioned medium were resolved under non-reducing conditions in a $10 \%$ polyacrylamide gel containing $1.0 \mathrm{mg} / \mathrm{ml}$ gelatin (porcine skin, 300-bloom, Sigma, St. Louis, MO). After electrophoresis, the gels were washed twice at room temperature for 30 minutes in $2.5 \%$ Triton X-100, subsequently washed in buffer containing $50 \mathrm{mM}$ Tris- $\mathrm{HCl}$, $150 \mathrm{mM} \mathrm{NaCl}, 5 \mathrm{mM} \mathrm{CaCl}_{2}, 1 \mu \mathrm{M} \mathrm{ZnCl}_{2}, 0.05 \%$ Brij$35,0.02 \% \mathrm{NaN} 3$ at $\mathrm{pH} 7.5$ and incubated in this buffer at $37^{\circ} \mathrm{C}$ for 24 hours. Thereafter, the gels were stained with $0.5 \%(\mathrm{w} / \mathrm{v})$ Coomassie brilliant blue R-250 (SigmaAldrich) for 30 minutes, lightly destained in methanol: acetic acid:water (3:1:6) and finally stored in 5\% acetic acid. Identification of each gelatinase band was done in accordance to the molecular weight, using purified human recombinant pro-MMP-2 and pro-MMP-9 (Calbiochem, USA) as standard (0.5 ng). Gels were scanned in the transmissive mode at 16-bit color/600 dpi (Epson Perfection 3490, Epson, CA) and stored in tiff format. Images were processed extracting the blue channel signal, converted to black and white and inverted for quantitation of the integrated optical density of gelatinolytic activities using the ImageJ v.1.34 software.

\section{Fluorescence Studies}

Immunofluorescence was performed for B2R. Cells were seeded at a concentration of 80,000 cells/well on cover slides in 24-well plates for 24 hours and washed 3 times with cold PBS and fixed with methanol at $-20^{\circ} \mathrm{C}$ for 20 minutes. Then washed with buffer PBS and incubated with protein block (Cas-Block, Zymed Laboratories, USA) serum free for 30 minutes in a humidified chamber. Cells were incubated with anti-B2R (anti-B2R 1:1000) overnight. Cells were washed twice for 5 minutes with PBS/Tween $200.1 \%$ and PBS, and incubated for 2 hours with anti-mouse-Rhodamine (PBS/1\%, BSA) (1:40) (Pierce, USA). The nuclei were stained with DAPI (Pierce, USA) and the sections were mounted with Vectashield (Vector Laboratories, Inc, USA). Microphotographs were obtained with an AX.10 microscope (Carl Zeiss) attached to a Nikon CoolPix 4500 camera adapted with an epi-ilumination mercury lamp (MBO 100, Leistungselektronik JENA GmbH).

The identification of morphological changes in the actin cytoskeleton was performed using FITC-conjugated phalloidin (Molecular Probes). Briefly, 10,000 cells were seeded on coverslips, and incubated with culture medium with $\mathrm{BK}(10.0 \mu \mathrm{Mol} / \mathrm{L})$, BK plus preincubation with HOE-140 $(10.0 \mu \mathrm{Mol} / \mathrm{L})$ and control conditions for 18 hours. The cells were rinsed with PBS and fixed in 4\% paraformaldehyde in PBS for 15 minutes at room temperature. To quench the excess of aldehyde, $0.1 \mathrm{M}$ glycine in PBS was added for 5 minutes. Cells were permeabilized with $0.1 \%$ Triton-X100 in PBS for $1 \mathrm{~min}$ and incubated with FITC-labelled phalloidin (1:100) in PBS for 15 minutes, finally cells were rinsed 3 times for 5 minutes in PBS, and mounted for microscopy with Vectashield. As above, microphotographs were obtained with an AX.10 microscope attached to a Nikon CoolPix 4500 camera adapted with an epi-ilumination mercury lamp. A blinded observer counted the number of filopodia connecting two cells in one $115-\mu \mathrm{m}^{2}$ rectangle per coverslip in at least 10 images from each experiment. The total number was then determined with ImageJ software, version 134. In addition, images were complemented by confocal laser scanning microscopy with an Olympus FluoView 1000 (Olympus UK).

\section{Statistical Analysis}

Results are expressed as mean \pm SE. One-way analysis of variance, followed by Tukey's Multiple Comparison post-hoc test, was used to test for differences between the different interventions and study periods with SPSS v10 (SPSS Inc.). A $P<0.05$ was considered significant. 


\section{Results}

Immunocytochemical detection of kininogen, kallikrein, the B1 and B2 receptors in HTR-8/SVneo cells

All cells expressed the components of the KKS (kallikrein, the $B 2 R$ and the $B 1 R$ ), as well as MMP-2 and MMP-9. The staining pattern for $\mathrm{Kal}$, the B2R and MMP-9 was diffuse, punctuate for B1R and granular for MMP-2. Cells incubated in the presence of serum expressed punctuate immunostaining for kininogen; however no signal was obtained when cells were deprived of serum for 24 hours. (Figure 1A). This finding supports the view that in vivo endogenous bradykinin likely derives from Kal acting on trapped circulating kininogen.

All cells were cytokeratin positive. Negative controls with cells incubated with mouse IgG serum and rabbit IgG fraction yielded no staining. (Figure 1B).
Effects of bradykinin and its antagonists on the migratory capacity of HTR-8/SVneo cells

The migration observed after incubating with BK (10.0 $\mu \mathrm{Mol} / \mathrm{L}$ ) for 6 hours was minimal and showed no differences among the experimental conditions. At 24 hours wounds in all conditions were closed. However, observations at 18 hours showed that BK induced a 3 -fold increase in the migration index as compared to controls $(3.39 \pm 0.27$ versus $1.00 \pm 0.04 ; P<0.001 ; \mathrm{n}=4$, respectively), and was completely blocked with the $\mathrm{B} 2 \mathrm{R}$ antagonist HOE-140 (0.86 $\pm 0.39 ; P<0.001 ; \mathrm{n}=4) \mathrm{On}$ the other hand, incubation with the B1R agonist LDBK, with or without preincubation with its antagonist AB1R, had no effect on the migratory capacity of HTR-8/SVneo cells. (Figure 2A and 2B).

We considered that wound healing was due to cell migration, and not to proliferation, given that $10 \mu \mathrm{Mol} / \mathrm{L}$

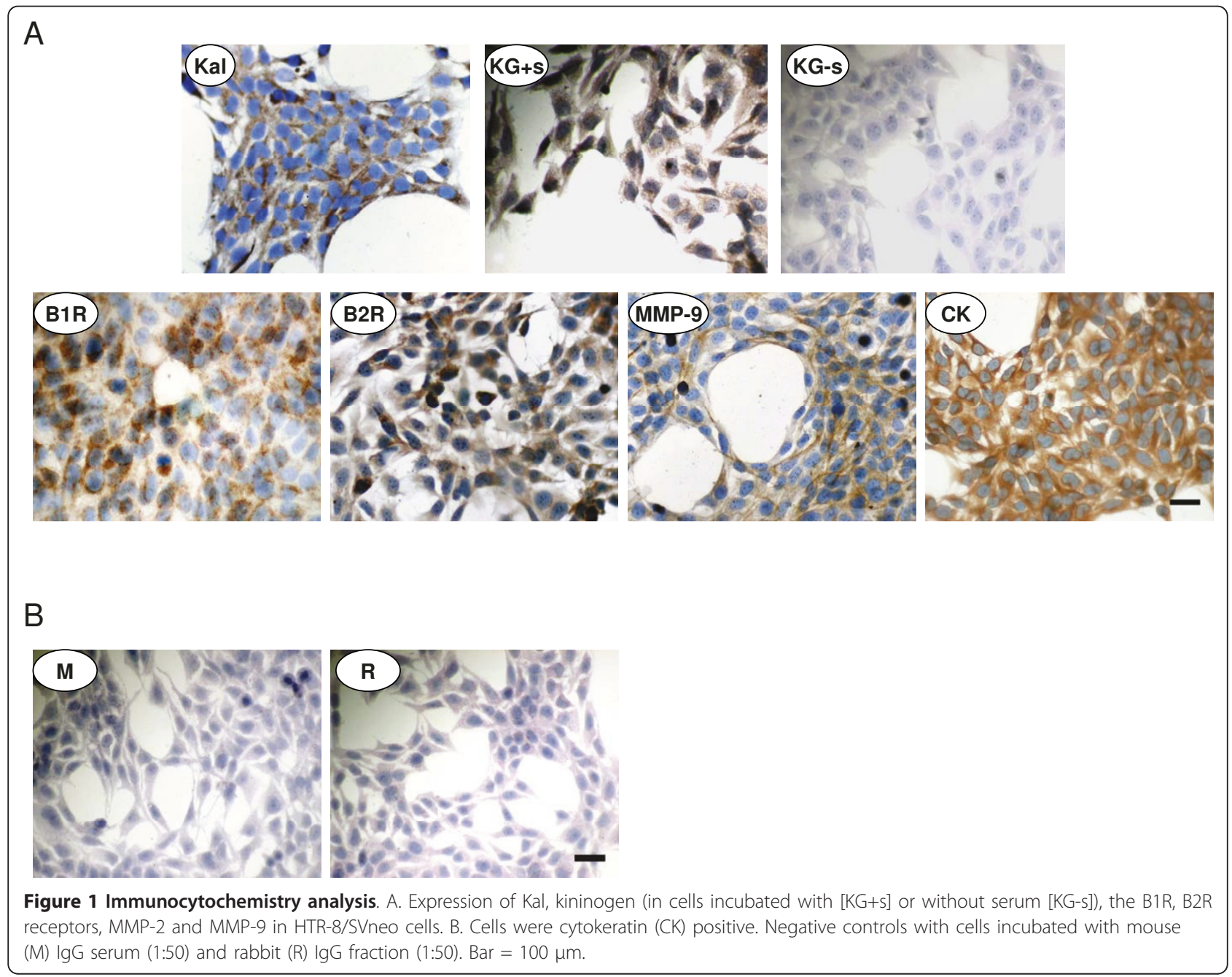




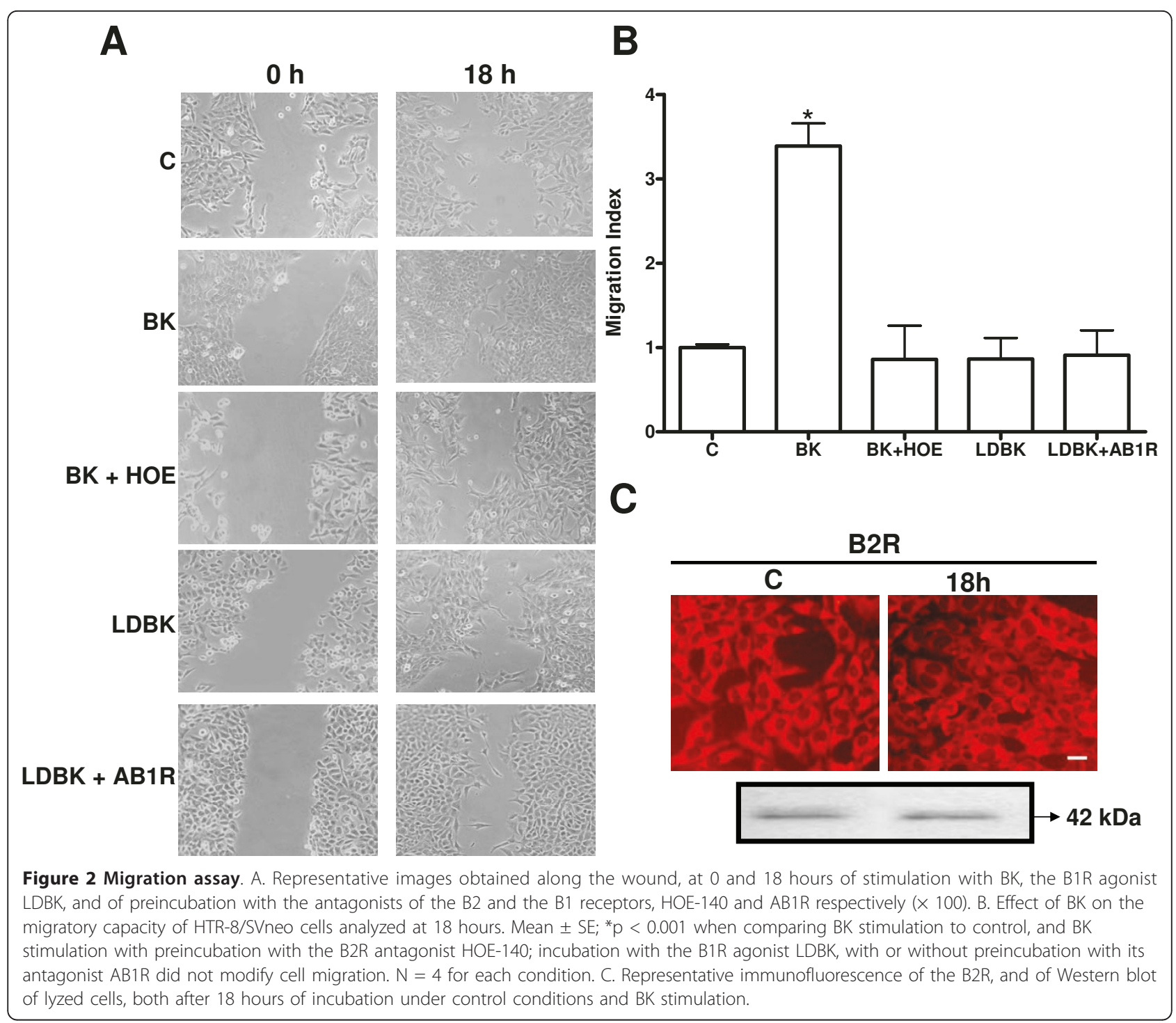

BK for 18 hours did not change the proliferation ratio between treated and untreated cells $(1.06 \pm 0.03, \mathrm{n}=3)$. No changes were observed in the content of the B2R at 18 hours, which yielded bands with a molecular weight of approximately $42 \mathrm{kDa}$ (Figure 2C). The absence of differences in cell proliferation, viable cells and expression of the B2R between control conditions and BK stimulation supports that bradykinin stimulation enhances migration through its binding to the B2R.

\section{Effects of bradykinin and its antagonists on the invasive capacity of HTR-8/SVneo cells}

Bradykinin $(10 \mu \mathrm{Mol} / \mathrm{L})$ in the culture media of the upper and the lower chambers of the invasion well increased the invasion index by 2 -fold at 18 hours as compared to controls $(2.50 \pm 0.44$ vs.1.00 $\pm 0.3 ; P<$ $0.05 ; \mathrm{n}=6)$. This increase was totally abolished by preincubation with $\mathrm{B} 2 \mathrm{R}$ antagonist $\mathrm{HOE}-140$ (0.72 \pm 0.05; $P<0.05 ; \mathrm{n}=3$ ). Incubation with the $\mathrm{B} 1 \mathrm{R}$ agonist LDBK, in the absence or presence of its antagonist $A B 1 R$ for 30 minutes, had no effect on the invasive capacity of the cells (Figure 3A and 3B).

\section{Effect of bradykinin on the formation of filopodia in HTR-8/SVneo cells}

In areas connecting two cells, BK $(10.0 \mu \mathrm{Mol} / \mathrm{L})$ induced a 3 -fold increase in the number of filopodia at 18 hours as compared to controls $(20.4 \pm 0.8$ vs. $6.47 \pm 0.4 ; P<$ $0.001 ; \mathrm{n}=3)$. This effect was abolished when the cells were preincubated with the B2R antagonist HOE-140 $(8.3 \pm 0.8 ; P<0.001, \mathrm{n}=3)$ (Figure $4 \mathrm{~A}$ and $4 \mathrm{~B})$. This finding confirms the effect of the $\mathrm{B} 2 \mathrm{R}$ on the modifications of the actin cytoskeleton that contribute to migration. 


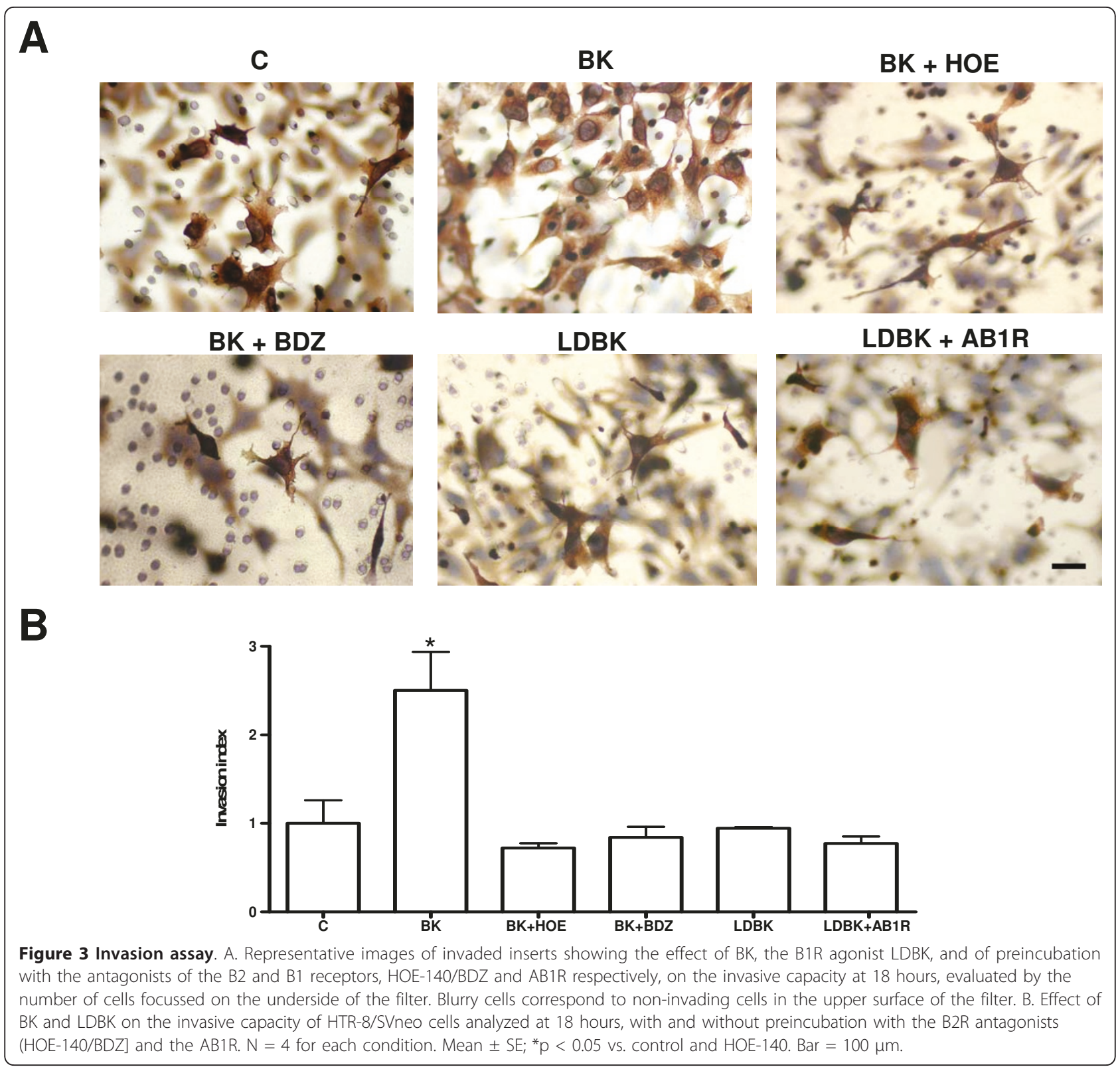

Effect of bradykinin on the release of MMP-2 and MMP-9 The gelatinase activity of MMP-9 and MMP-2 in the culture media showed no variation when incubated with BK for different periods (2 minutes, 2, 4, 6, 18, 24 and 48 hours), or concentrations (1.0, 10.0 and $100 \mu \mathrm{Mol} / \mathrm{L})$. Figure 5 depicts the gelatinase activity of 3 experiments after 18 hours of incubation in control conditions $(C)$ or under stimulation with BK $10 \mu \mathrm{Mol} / \mathrm{L}$.

\section{Discussion}

To our knowledge, this is the first report demonstrating an action of bradykinin on trophoblast migration and invasion, effects which can be attributed solely to activation of the B2R. In addition, this study adds kallikrein and the B2 receptor to the many factors shared by the human trophoblast and HTR-8/SVneo cells, underscoring their similarities. Though the promigratory and proinvasive effects of B2R stimulation were observed in immortalized HTR-8/SVneo trophoblasts, which are not genetically identical to primary CTB or EVT [47], and further studies are needed in human trophoblasts, the expression of the B2R in human extravillous trophoblasts [16] supports its participation in the invasive phenotype of genuine trophoblasts.

In order to elucidate the effect of bradykinin on cell migration/invasion, it is necessary to consider migration and invasion in the context of the repetitive conformational changes of the cytoskeleton involved in these 


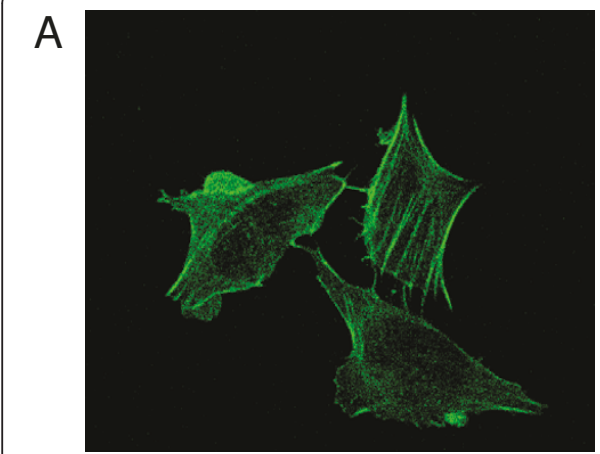

Control

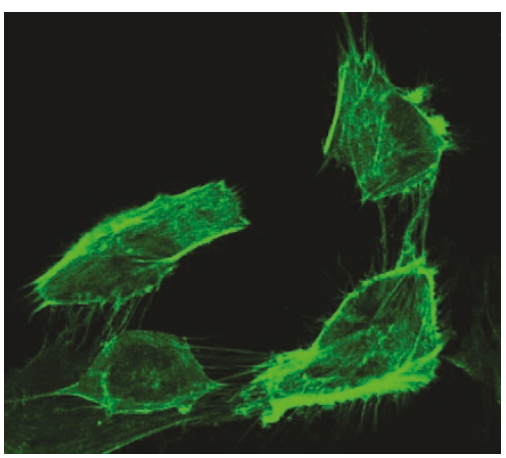

BK

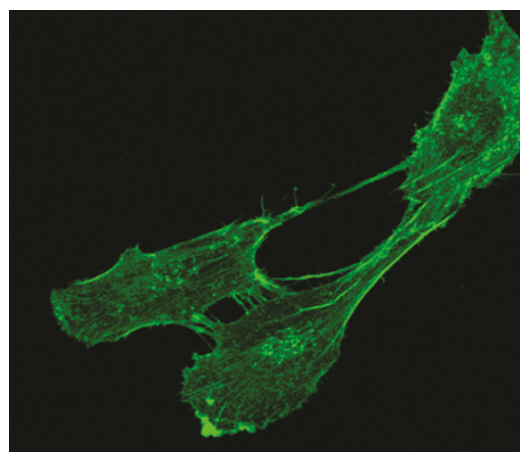

$\mathrm{BK}+\mathrm{HOE}$

B

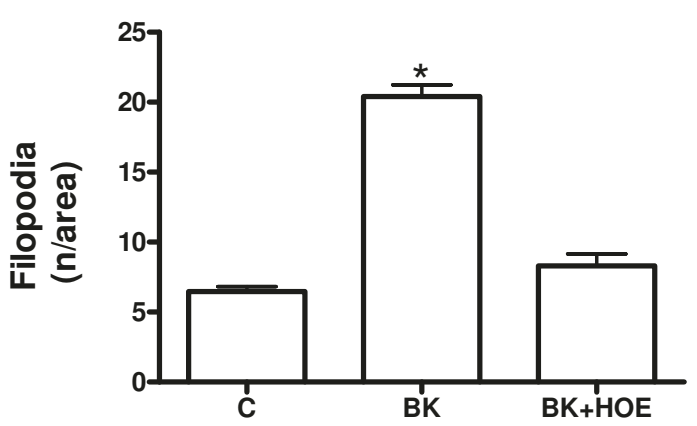

Figure 4 Formation of filopodia in HTR-8/SVneo cells. A. Representative images of filopodias in the area connecting two cells after 18 hours of stimulation with BK $(10.0 \mu \mathrm{Mol} / \mathrm{L})$, and with BK $(10.0 \mu \mathrm{Mol} / \mathrm{L})$ plus the antagonist of the B2R, HOE-140 $(10.0 \mu \mathrm{Mol} / \mathrm{L})$ obtained with a laser scanning confocal microscope. B. Effect of BK and BK plus HOE-140 on the number of filopodia. Mean $\pm \mathrm{SE} ;{ }^{*} p<0.001 \mathrm{vs}$. control and HOE-140, $\mathrm{n}=3$. Bar $=100 \mu \mathrm{m}$.

processes [48]. The initial migratory response of a cell is to polarize and form cellular protrusions, such as actin microspikes, filopodia and lamellipodia, which push forward the leading edge of the cell to invade the surrounding tissue. The formation of these protrusions requires the polymerization of actin, and their stability depends on adherence to the extracellular matrix and the adjacent cells via transmembrane receptors linked to the actin cytoskeleton $[27,49]$. The increase in the number of filopodia in HTR-8/SVneo cells incubated with bradykinin confirmed these modifications of the actin cytoskeleton.

It has been shown that the formation of filopodia, actin microspikes, and lamellipodia are dependent on Cdc42 and Rac1. In concordance with our observations in HTR-8/SVneo cells, bradykinin promotes the formation of Cdc42-dependent membrane protrusions in fibroblasts [33], as well as peripheral actin microspikes and membrane ruffles with a temporal pattern similar to that observed with Cdc42Hs [48]. In human umbilical vein endothelial cells, Cdc42 is specifically activated by bradykinin [50]. In endothelial progenitor cells, BK stimulates the formation of filopodia and recruitment of Rac1 to the cell membrane; while the BK-induced polarization, formation of filopodia, and migration were inhibited by the B2R antagonist HOE-140 [29]. Part of the effects we observed after bradykinin stimulation could be mediated by the pro-invasive Cdc42 and Rac1dependent responses provoked by $\mathrm{PGE}_{2}$, also present in HTR-8/SVneo cells $[10,51,52]$, since the B2R mediates COX-2 induced $\mathrm{PGE}_{2}$ release in vascular smooth muscle and tumoral cells $[53,54]$.

Apart from its conformational changes, a migrating cell must detach from the ECM and neighboring cells. In this regard, matrix metalloproteinases (MMPs) are believed to be a dominant system in trophoblast invasion [9]. Stimulation of the B2R induces MMP overexpression and cell migration in a rat astroglial cell line [39], while the B1R induces release of MMP-2 and MMP-9 in breast cancer cells [37]. Co-localization of 


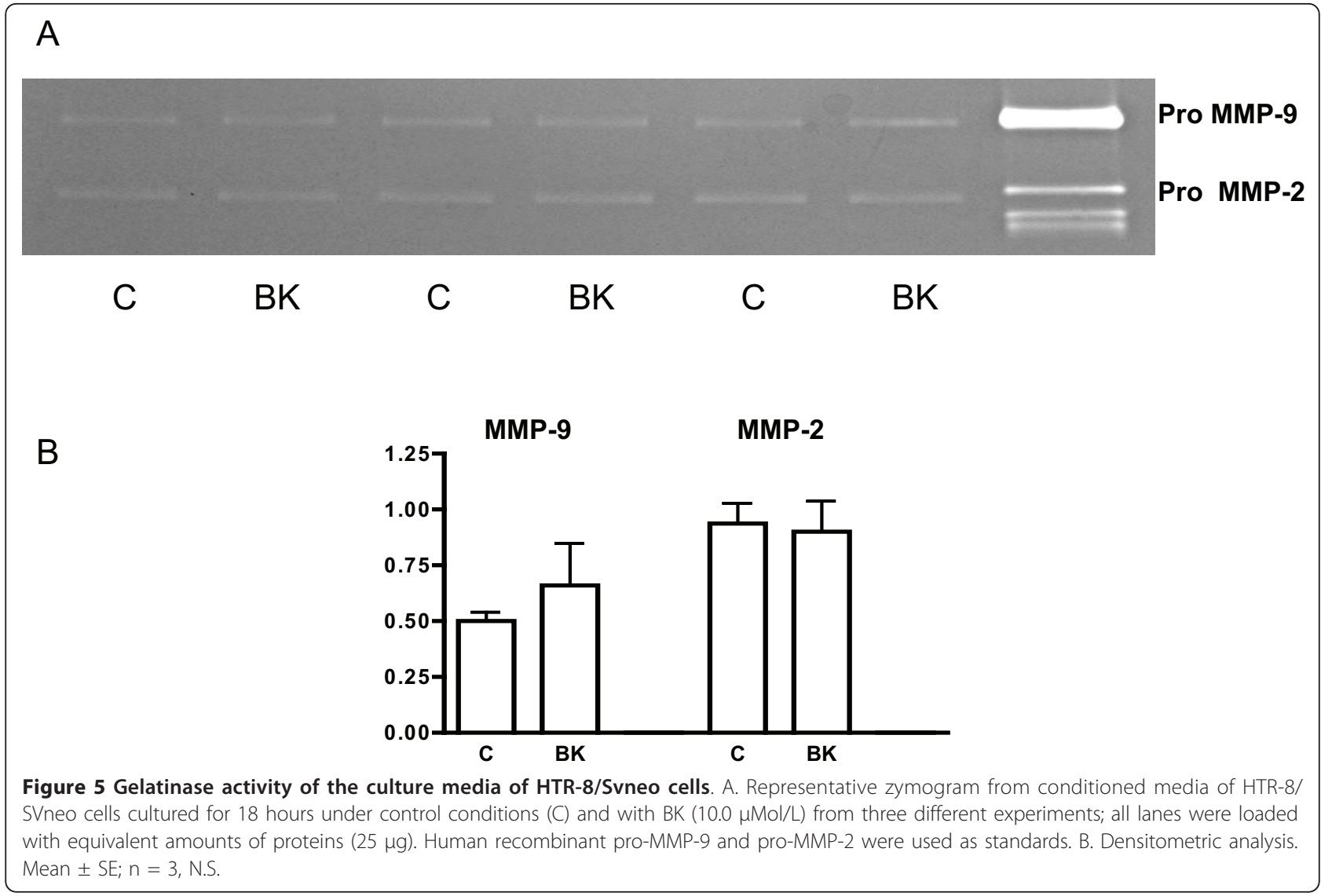

MMP-9 and the B2R was observed in our previous studies in guinea-pig extravillous trophoblast [46]. The co-localization of MMP-9 and MMP-2 with the B2R was confirmed in HTR-8/SVneo cells by immunohistochemistry and enzymatic activity in this study. In spite of the functional and spatial associations between bradykinin and MMPs, no changes were observed in MMP-2 and MMP-9 activity in culture media after bradykinin stimulation.

The participation of plasminogen activators (PA) in BK enhanced invasion deserves further exploration. The B2R stimulates tissue (t)PA release from human endothelium [55], HTR-8/SVneo cells express urokinase (u)PA and tPA mRNA $[36,40,41,56]$, uPA has been detected in extravillous trophoblasts, and gonadotrophin releasing hormones I and II, key facilitators of trophoblast invasion, are capable of up-regulating uPA [57].

Can the promigratory and invasive effect of BK be linked to what is already known about the modulation of the KKS system in pregnancy? In normal pregnant women the surge in urinary kallikrein reaches its maximum between 8 to 12 weeks, a stage of active trophoblast invasion [58]. On the contrary, reduced urinary kallikrein levels are observed in hypertensive pregnancies [59], and at 16 weeks represent one of the best predictors of preeclampsia [60]. Having demonstrated kallikrein and the B2R in cells involved in placentation in humans, guinea-pigs and rats [16,19-21,23,45,46,61,62], we hypothesize that a defective response of the KKS at the primordial target, the utero-placental interface could impair trophoblast invasion. This impairment could derive in part, from dimers of the angiotensin II type 1 and the $\mathrm{B} 2$ receptors observed in preeclampsia, which enhance the effect of angiotensin II and blunt the response to B2R stimulation [63,64]. Unfortunately, circulating levels of bradykinin are difficult to determine due to rapid degradation and artifactual generation of the peptide during sampling. Though these difficulties have been circumvented by determining a stable plasma metabolite-BK1-5-by liquid chromatography-tandem mass spectrometry [55], even if circulating levels could be titrated in normotensive and hypertensive pregnancies, the tissue bradykinin content would be impossible to define.

\section{Perspectives}

This first report demonstrating a B2R-dependent stimulatory effect of bradykinin on trophoblast migration and invasion in an immortalized first trimester cell line supports the participation of the KKS in the local 
adaptations of pregnancy in a relatively recently described non-vasoactive role. Since the gene expression profile of HTR-8/SVneo is related-but dissimilar to primary CTB or EVT [47]-further studies, ideally in animals that share an analogous pattern of trophoblast invasion with humans, or in vivo complex models, as cocultured trophoblasts and endothelial cells or explants from early pregnancies with cognate outcomes are warranted $[65,66]$.

\section{Acknowledgements}

The authors are grateful to CH Graham from Queen's University, Kingston, Ontario, Canada for his gift of HTR-8/SVneo cells, to CD Figueroa PhD for his advice throughout the study, and to Eduardo Machuca MD-PhD and Eve E Slater MD for their helpful editorial comments. This work was supported by Fondecyt grant 1080228 and by a private donation.

\section{Author details}

${ }^{1}$ Centro de Investigaciones Médicas, Escuela de Medicina Pontificia Universidad Católica, Santiago, Chile. ${ }^{2}$ Departamento de Nefrología, Escuela de Medicina Pontificia Universidad Católica, Santiago, Chile.

\section{Authors' contributions}

RE participated in the design of the study, performed the migration and the invasion assays, the statistical analysis and drafted the manuscript. JC performed the immunohistochemistry, and with FL did the Western blots. JC and GV conceived the study, participated in its design and coordination, and wrote the manuscript. All authors read and approved the final manuscript.

\section{Competing interests}

The authors declare that they have no competing interests.

Received: 9 March 2011 Accepted: 5 July 2011 Published: 5 July 2011

\section{References}

1. Kaufmann P, Black S, Huppertz B: Endovascular trophoblast invasion: implications for the pathogenesis of intrauterine growth retardation and preeclampsia. Biol Reprod 2003, 69:1-7.

2. Red-Horse K, Zhou Y, Genbacev O, Prakobphol A, Foulk R, McMaster M, Fisher SJ: Trophoblast differentiation during embryo implantation and formation of the maternal-fetal interface. J Clin Invest 2004, 114:744-754.

3. Lunghi L, Ferretti ME, Medici S, Biondi C, Vesce F: Control of human trophoblast function. Reprod Biol Endocrinol 2007, 5:6.

4. Silasi M, Cohen B, Karumanchi SA, Rana S: Abnormal placentation, angiogenic factors, and the pathogenesis of preeclampsia. Obstet Gynecol Clin North Am 37:239-253.

5. Roberts $J M$, Hubel CA: The two stage model of preeclampsia: variations on the theme. Placenta 2009, 30(Suppl A):S32-37.

6. Norwitz ER: Defective implantation and placentation: laying the blueprint for pregnancy complications. Reprod Biomed Online 2006, 13:591-599.

7. Goldman-Wohl D, Yagel S: Regulation of trophoblast invasion: from normal implantation to pre-eclampsia. Mol Cell Endocrinol 2002, 187:233-238.

8. Zhou Y, Genbacev O, Fisher SJ: The human placenta remodels the uterus by using a combination of molecules that govern vasculogenesis or leukocyte extravasation. Ann N Y Acad Sci 2003, 995:73-83.

9. Staun-Ram E, Goldman S, Gabarin D, Shalev E: Expression and importance of matrix metalloproteinase 2 and 9 (MMP-2 and -9) in human trophoblast invasion. Reprod Biol Endocrinol 2004, 2:59.

10. Lala PK, Nicola C, Chakraborty C: Effects of $\mathrm{PGE}_{2}$ on human trophoblast proliferation and migration. Placenta 2010, 27:928-929.

11. Demir-Weusten AY, Seval Y, Kaufmann P, Demir R, Yucel G, Huppertz B: Matrix metalloproteinases-2, -3 and -9 in human term placenta. Acta Histochem 2007, 109:403-412

12. Damsky CH, Librach C, Lim KH, Fitzgerald ML, McMaster MT, Janatpour M, Zhou Y, Logan SK, Fisher SJ: Integrin switching regulates normal trophoblast invasion. Development 1994, 120:3657-3666.
13. Sargent IL, Borzychowski AM, Redman CW: Immunoregulation in normal pregnancy and pre-eclampsia: an overview. Reprod Biomed Online 2006, 13:680-686.

14. Nanaev A, Chwalisz K, Frank HG, Kohnen G, Hegele-Hartung C, Kaufmann P: Physiological dilation of uteroplacental arteries in the guinea pig depends on nitric oxide synthase activity of extravillous trophoblast. Cell Tissue Res 1995, 282:407-421.

15. Valdés G, Kaufmann P, Corthorn J, Erices R, Brosnihan KB, JoynerGrantham J: Vasodilator factors in the systemic and local adaptations to pregnancy. Reprod Biol Endocrinol 2009, 7:79.

16. Corthorn J, Germain AA, Chacón C, Rey S, Soto GX, Figueroa CD, MullerEsterl W, Duarte I, Valdés G: Expression of kallikrein, bradykinin B2 receptor, and endothelial nitric oxide synthase in placenta in normal gestation, preeclampsia, and placenta accreta. Endocrine 2006, 29:491-499.

17. Calixto JB, Medeiros R, Fernandes ES, Ferreira J, Cabrini DA, Campos MM Kinin B1 receptors: key G-protein-coupled receptors and their role in inflammatory and painful processes. Br J Pharmacol 2004, 143:803-818.

18. Moreau ME, Garbacki N, Molinaro G, Brown NJ, Marceau F, Adam A: The kallikrein-kinin system: current and future pharmacological targets. J Pharmacol Sci 2005, 99:6-38.

19. Valdés G, Germain AM, Corthorn J, Chacon C, Figueroa CD, Muller-Esterl W: Tissue kallikrein and bradykinin B2 receptor in human uterus in luteal phase and in early and late gestation. Endocrine 2001, 16:207-215.

20. Valdés G, Chacón C, Corthorn J, Figueroa CD, Germain AM: Tissue kallikrein in human placenta in early and late gestation. Endocrine 2001, 14:197-204.

21. Figueroa CD, Chacón C, Corthorn J, Ehrenfeld P, Müller-Esterl W, Valdés G: Temporospatial changes of kinin B2 receptors during the estrous cycle and pregnancy in the rat uterus. Biol Reprod 2001, 64:1590-1599.

22. Buchinger $\mathrm{P}$, Rehbock J: The bradykinin B2-receptor in human decidua. Semin Thromb Hemost 1999, 25:543-549

23. Valdés $G$, Erices $R$, Chacón $C$, Corthorn J: Angiogenic, hyperpermeability and vasodilator network in utero-placental units along pregnancy in the guinea-pig (Cavia porcellus). Reprod Biol Endocrinol 2008, 6:13.

24. Lauffenburger DA, Horwitz AF: Cell migration: a physically integrated molecular process. Cell 1996, 84:359-369.

25. Mitchison TJ, Cramer LP: Actin-based cell motility and cell locomotion. Cell 1996, 84:371-379.

26. Pollard TD, Borisy GG: Cellular motility driven by assembly and disassembly of actin filaments. Cell 2003, 112:453-465.

27. Ridley AJ, Schwartz MA, Burridge K, Firtel RA, Ginsberg MH, Borisy G, Parsons JT, Horwitz AR: Cell migration: integrating signals from front to back. Science 2003, 302:1704-1709.

28. Liesmaa I, Leskinen HK, Kokkonen JO, Ruskoaho H, Kovanen PT, Lindstedt KA: Hypoxia-induced expression of bradykinin type-2 receptors in endothelial cells triggers NO production, cell migration, and angiogenesis. J Cell Physiol 2009, 221:359-366.

29. Krankel N, Katare RG, Siragusa M, Barcelos LS, Campagnolo P, Mangialardi G, Fortunato O, Spinetti G, Tran N, Zacharowski K, et al: Role of kinin B2 receptor signaling in the recruitment of circulating progenitor cells with neovascularization potential. Circ Res 2008, 103:1335-1343.

30. Ehrenfeld $P$, Millan $C$, Matus $C E$, Figueroa JE, Burgos RA, Nualart $F$, Bhoola KD, Figueroa CD: Activation of kinin $B 1$ receptors induces chemotaxis of human neutrophils. J Leukoc Biol 2006, 80:117-124.

31. Paegelow I, Trzeczak S, Bockmann S, Vietinghoff G: Migratory responses of polymorphonuclear leukocytes to kinin peptides. Pharmacology 2002, 66:153-161.

32. McFadden RG, Vickers KE: Bradykinin augments the in vitro migration of nonsensitized lymphocytes. Clin Invest Med 1989, 12:247-253.

33. Kozma R, Ahmed S, Best A, Lim L: The Ras-related protein Cdc42Hs and bradykinin promote formation of peripheral actin microspikes and filopodia in Swiss 3T3 fibroblasts. Mol Cell Biol 1995, 15:1942-1952.

34. Bertram CM, Baltic S, Misso NL, Bhoola KD, Foster PS, Thompson PJ, FogelPetrovic M: Expression of kinin B1 and B2 receptors in immature, monocyte-derived dendritic cells and bradykinin-mediated increase in intracellular Ca2+ and cell migration. J Leukoc Biol 2007, 81:1445-1454.

35. Ifuku M, Farber K, Okuno Y, Yamakawa Y, Miyamoto T, Nolte C, Merrino VF, Kita S, Iwamoto T, Komuro I, et al: Bradykinin-induced microglial migration mediated by $\mathrm{B} 1$-bradykinin receptors depends on $\mathrm{Ca} 2+$ influx via reverse-mode activity of the $\mathrm{Na}+/ \mathrm{Ca} 2+$ exchanger. J Neurosci 2007, 27:13065-13073. 
36. Yang WH, Chang JT, Hsu SF, Li TM, Cho DY, Huang CY, Fong YC, Tang CH: Bradykinin enhances cell migration in human chondrosarcoma cells through BK receptor signaling pathways. J Cell Biochem 2010, 109:82-92.

37. Ehrenfeld P, Conejeros I, Pavicic MF, Matus CE, González CB, Quest AF, Bhoola KD, Poblete MT, Burgos RA, Figueroa CD: Activation of kinin B1 receptor increases the release of metalloproteases-2 and -9 from both estrogen-sensitive and-insensitive breast cancer cells. Cancer Lett 2011, 301:106-118.

38. Baba K, Yamaguchi O: Effects of bradykinin on cytoplasmic calcium and motility in murine bladder tumor cells. J Urol 2001, 165:259-262.

39. Hsieh HL, Wu CY, Yang CM: Bradykinin induces matrix metalloproteinase9 expression and cell migration through a PKC-delta-dependent ERK/Elk1 pathway in astrocytes. Glia 2008, 56:619-632.

40. Graham CH: Effect of transforming growth factor-beta on the plasminogen activator system in cultured first trimester human cytotrophoblasts. Placenta 1997, 18:137-143.

41. Graham CH, Fitzpatrick TE, McCrae KR: Hypoxia stimulates urokinase receptor expression through a heme protein-dependent pathway. Blood 1998, 91:3300-3307.

42. Graham CH, Hawley TS, Hawley RG, MacDougall JR, Kerbel RS, Khoo N Lala PK: Establishment and characterization of first trimester human trophoblast cells with extended lifespan. Exp Cell Res 1993, 206:204-211.

43. Lash GE, Hornbuckle J, Brunt A, Kirkley M, Searle RF, Robson SC, Bulmer JN: Effect of low oxygen concentrations on trophoblast-like cell line invasion. Placenta 2007, 28:390-398.

44. Kilburn BA, Wang J, Duniec-Dmuchowski ZM, Leach RE, Romero R, Armant DR: Extracellular matrix composition and hypoxia regulate the expression of HLA-G and integrins in a human trophoblast cell line. Biol Reprod 2000, 62:739-747.

45. Corthorn J, Valdés G: Variations in uterine kallikrein during cycle and early pregnancy in the rat. Biol Reprod 1994, 50:1261-1264.

46. Corthorn J, Rey S, Chacon C, Valdés G: Spatio-temporal expression of MMP-2, MMP-9 and tissue kallikrein in uteroplacental units of the pregnant guinea-pig (Cavia porcellus). Reprod Biol Endocrinol 2007, 5:27.

47. Bilban M, Tauber S, Haslinger P, Pollheimer J, Saleh L, Pehamberger $H$ Wagner O, Knofler M: Trophoblast invasion: assessment of cellular models using gene expression signatures. Placenta 2010, 31:989-996.

48. Nobes CD, Hall A: Rho GTPases control polarity, protrusion, and adhesion during cell movement. J Cell Biol 1999, 144:1235-1244.

49. Brakebusch C, Fassler R: The integrin-actin connection, an eternal love affair. Embo / 2003, 22:2324-2333.

50. Petrovic N, Schacke W, Gahagan JR, O'Conor CA, Winnicka B, Conway RE, Mina-Osorio $P$, Shapiro LH: CD13/APN regulates endothelial invasion and filopodia formation. Blood 2007, 110:142-150.

51. Nicola C, Lala PK, Chakraborty C: Prostaglandin $E_{2}$-mediated migration of human trophoblast requires RAC1 and CDC42. Biol Reprod 2008, 78:976-982.

52. Horita H, Kuroda E, Hachisuga T, Kashimura M, Yamashita U: Induction of prostaglandin $E_{2}$ production by leukemia inhibitory factor promotes migration of first trimester extravillous trophoblast cell line, HTR-8/ SVneo. Hum Reprod 2007, 22:1801-1809.

53. Zhang W, Bhola N, Kalyankrishna S, Gooding W, Hunt J, Seethala R, Grandis JR, Siegfried JM: Kinin B2 receptor mediates induction of cyclooxygenase-2 and is overexpressed in head and neck squamous cell carcinomas. Mol Cancer Res 2008, 6:1946-1956.

54. Bradbury DA, Newton R, Zhu YM, El-Haroun H, Corbett L, Knox AJ: Cyclooxygenase-2 induction by bradykinin in human pulmonary artery smooth muscle cells is mediated by the cyclic AMP response element through a novel autocrine loop involving endogenous prostaglandin $E_{2}$, E-prostanoid 2 (EP2), and EP4 receptors. J Biol Chem 2003, 278:49954-49964.

55. Brown NJ, Gainer JV, Murphey LJ, Vaughan DE: Bradykinin stimulates tissue plasminogen activator release from human forearm vasculature through $\mathrm{B}(2)$ receptor-dependent, NO synthase-independent, and cyclooxygenase-independent pathway. Circulation 2000, 102:2190-2196.

56. Huber AV, Saleh L, Bauer S, Husslein P, Knofler M: TNFalpha-mediated induction of PAl-1 restricts invasion of HTR-8/SVneo trophoblast cells. Placenta 2006, 27:127-136.

57. Chou CS, Zhu H, Shalev E, MacCalman CD, Leung PC: The effects of gonadotropin-releasing hormone $(\mathrm{GnRH})$ I and $\mathrm{GnRH}$ II on the urokinase-type plasminogen activator/plasminogen activator inhibitor system in human extravillous cytotrophoblasts in vitro. $J$ Clin Endocrinol Metab 2002, 87:5594-5603.

58. Valdés G, Corthorn J, Oyarzún E, Berríos C, Foradori A, Germain AM, L V: Urinary kallikrein excretion in the human menstrual cycle, normal pregnancy and lactation. Prenat Neonat Med 1998, 3:474-481.

59. Elebute $\mathrm{OA}$, Mills $\mathrm{H}_{\mathrm{H}}$ : Urinary kallikrein in normal and hypertensive pregnancies. Perspect Nephrol Hypertens 1976, 5:329-338.

60. Millar JG, Campbell SK, Albano JD, Higgins BR, Clark AD: Early prediction of pre-eclampsia by measurement of kallikrein and creatinine on a random urine sample. Br J Obstet Gynaecol 1996, 103:421-426.

61. Valdés G, Fiqueroa CD, Corthorn J: Temporospatial changes of kallikreinlike enzymes during the estrous cycle and pregnancy in the rat uterus. Biol Reprod 1996, 55:236-245.

62. Valdés G, Corthorn J, Scicli AG, Gaete V, Soto J, Ortíz ME, Foradori A Saed GM: Uterine kallikrein in the early pregnant rat. Biol Reprod 1993, 49:802-808.

63. Quitterer $\mathrm{U}$, Lother $H$, Abdalla S: AT1 receptor heterodimers and angiotensin II responsiveness in preeclampsia. Semin Nephrol 2004, 24:115-119.

64. AbdAlla S, Lother $H$, el Massiery A, Quitterer U: Increased AT(1) receptor heterodimers in preeclampsia mediate enhanced angiotensin II responsiveness. Nat Med 2001, 7:1003-1009.

65. Seeho SK, Park JH, Rowe J, Morris JM, Gallery ED: Villous explant culture using early gestation tissue from ongoing pregnancies with known normal outcomes: the effect of oxygen on trophoblast outgrowth and migration. Hum Reprod 2008, 23:1170-1179.

66. Campbell S, Rowe J, Jackson CJ, Gallery ED: Interaction of cocultured decidual endothelial cells and cytotrophoblasts in preeclampsia. Biol Reprod 2004, 71:244-252.

doi:10.1186/1477-7827-9-97

Cite this article as: Erices et al:: Bradykinin promotes migration and invasion of human immortalized trophoblasts. Reproductive Biology and Endocrinology 2011 9:97.

\section{Submit your next manuscript to BioMed Central and take full advantage of:}

- Convenient online submission

- Thorough peer review

- No space constraints or color figure charges

- Immediate publication on acceptance

- Inclusion in PubMed, CAS, Scopus and Google Scholar

- Research which is freely available for redistribution
C Biomed Central 